Article

\title{
Achieving Integrated Daylighting and Electric Lighting Systems: Current State of the Art and Needed Research
}

\author{
Gregory D. Thomson ${ }^{1, *}$, Robert G. Davis ${ }^{2}$, Luís Fernandes ${ }^{3}$ and Taoning Wang ${ }^{3}$ \\ 1 PlanArchology LLC, Berkeley, CA 94710, USA \\ 2 Pacific Northwest National Laboratory, Portland, OR 97204, USA; Robert.Davis@pnnl.gov \\ 3 Lawrence Berkeley National Laboratory, Berkeley, CA 94720, USA; LLFernandes@lbl.gov (L.F.); \\ taoningwang@lbl.gov (T.W.) \\ * Correspondence: gregory.thomson@planarchology.com
}

check for

updates

Citation: Thomson, G.D.; Davis, R.G.; Fernandes, L.; Wang, T.

Achieving Integrated Daylighting and Electric Lighting Systems:

Current State of the Art and Needed Research. Energies 2021, 14, 3833.

https://doi.org/10.3390/

en14133833

Academic Editor:

Alessandro Cannavale

Received: 31 May 2021

Accepted: 22 June 2021

Published: 25 June 2021

Publisher's Note: MDPI stays neutral with regard to jurisdictional claims in published maps and institutional affiliations.

Copyright: (c) 2021 by the authors. Licensee MDPI, Basel, Switzerland. This article is an open access article distributed under the terms and conditions of the Creative Commons Attribution (CC BY) license (https:// creativecommons.org/licenses/by/ $4.0 /)$.

\begin{abstract}
This paper presents the results of a multi-disciplinary effort to clarify the state of the art and the state of practice, and necessary future research for creating the seamless integration and application of light in buildings, regardless of source, which is purposely modulated to illuminate surfaces and designed in a way that is comfortable, healthy, pleasing, cost-effective, and energy efficient. The authors unwrap the research, tools, and technical gaps preventing the full integration of electric lighting and daylighting with advanced façades through the coordination of lighting and windows research activities. The study and a stakeholder workshop captured current technology readiness levels (TRL), as well as research thrusts and implementation guidelines, and identified research priorities, presenting an analysis of the current landscape of lighting metrics-and which metrics are in the critical path for developing integrated daylighting and electric lighting systems, and their design, installation, and technology guidelines. In addition, the study defined stakeholder coordination, pathways to interoperable technology, and the value of viewing the work of the individual research areas holistically rather than in isolation.
\end{abstract}

Keywords: integrated lighting systems; daylighting; electric lighting

\section{Introduction}

Today's typical buildings have lighting systems that are often disconnected from the other building systems (e.g., energy management systems, other mechanical, electrical, plumbing, demand responses) and their control instruments. Daylighting systems are separated from electric lighting systems, and both are characteristically detached from other systems such as safety, security, communications, and information systems. Consequently, electric lighting systems are commonly not responsive to available daylighting as well as being static in their intensity, spectrum, and distribution. Standard transparent façade elements are not technically daylight systems, because they typically lack the design intention and performance characteristics necessary to be responsive to bioclimatic conditions (As of July 2020, all but nine states and two U.S. territories required that new construction meets or exceeds ASHRAE 90.1-2004, which requires, at a minimum, automatic shutoff of lighting in commercial buildings greater than 5000 square feet in size, with few exceptions. [http:/ / bcapcodes.org/code-status/commercial/: accessed on 20 July 2020]). More importantly, daylight and electric lighting systems are rarely integrated with each other. Being disconnected from the inputs and outputs of other building systems precludes the ability to acquire and utilize information about the occupation, status of systems, and interior and exterior environmental conditions. The outcome of this separation is that the standard building is not fulfilling the potential for creating dynamic and holistic lighting for building occupants.

In the context of this paper, daylighting systems are the active and static building envelope components (transparent and translucent glazing, coatings and light redirecting 
films, active and static attachments installed internally and externally), including skylights or other elements, that bring light to the building interior; electric lighting systems are the active and static sources (lamps, fixtures, luminaires, and sensors and controls), that supply light to the building interior ([Façade] attachments are products installed either internally or externally on a [building façade] that can serve a variety of purposes including: adding to the room aesthetic, protection, enhanced view and natural light, reducing draftiness, lessen glare and heat from the sun, or privacy. (https: / / aercnet.org/resources / window-attachments /: accessed on 20 July 2020)) [1]. The research needs presented in this paper explored the range and complexity of professional and industry best practices, research thrusts, and the dissemination pathways necessary for addressing how nextgeneration systems technologies, their modes of connection, integration, and optimization will overcome the challenges for future implementation. Integrated lighting will be part of the solution for short- and long-term building resilience. It is projected that integrated lighting systems may save more than 200 TBTU (relative to a 2030 baseline condition of 260 TBTU) in lighting energy use in office buildings [1]. Equally as important are the network of non-energy impacts effecting building occupants' overall health, comfort, and satisfaction.

This is important because the average American is inside nearly $90 \%$ of their time. There is no greater influence on health and well-being than where we spend our time [2]. It is evident, globally and locally, that we are in a time of substantial change and uncertainty, inclusive of the uncertainty about how our built environment will respond to external environmental conditions (e.g., extreme weather events, and other natural disasters), and the impact those conditions may have on the ability of buildings (individually and collectively) to operate as intended. Lighting in buildings (new and existing) in the future must be flexible to changes in the quantity and quality of daylight, information flows in connected systems, and to changes in occupant lighting requirements to optimize comfort, and well-being.

Integrating daylighting systems with electric lighting systems has been an ongoing project for researchers, practitioners, and industry for over thirty years. Building energy savings and energy demand reduction have been the primary emphasis of these efforts, which have focused on control optimization and application types [3]. Research during this period estimated that electric lighting controls that are responsive to daylight availability have the potential to save $50-80 \%$ of electric lighting systems energy [4,5]. Successful integration solutions are infrequently implemented despite the quantity of potential savings, and actual savings remain insufficiently close to estimates. "Post-occupancy studies carried out in real buildings have shown that the actual energy performance is invariably markedly worse than that predicted at the design stage [6]". In the period since the study in [5], little has changed-plainly, this is not a novel problem. Recent convergences of scientific and technical trends have increased the potential of the value proposition (and the chances of success), for realizing the design and implementation of fully integrated lighting systems. Those trends include significantly upgraded capabilities for modeling the behavior of light in spaces; the availability of spectrally tunable solid-state lighting (SSL); the maturing of internet-of-things connectivity (making real-time data exchange between building systems feasible); and sensors and controls technologies having markedly enhanced performance (at smaller sizes and lower costs). This technical progress should be viewed as supporting the design and delivery of the suitable type, quantity, and quality of light to building occupants, because there is growing scientific evidence of the importance of light on human health and well-being.

Despite the potential energy, comfort, and building operation benefits of achieving a more complete integration between the operation of daylighting and electric lighting systems, comprehensive assessments of the state of the professional practice and technology that are explicitly focused on the integration between daylighting and electric lighting systems are sparse in the literature, especially in what concerns the identification of critical research gaps to achieve such integration. Ne'eman [7] defined general principles for integrating daylighting and electric lighting, without very detailed considerations on the 
research needed to achieve such goals in practice. As far as integration is concerned, the main focus is on achieving it through the proper dimensioning of daylight openings; active controls are circumscribed to the electric lighting, with interactions between the façade and the electric lighting system taking place indirectly through photosensors that are part of the latter, rather than through deeper integration at the system level. More recent work, whether focused on system design [8,9], simulation methods [10], user experience [11], or case studies [11,12], is certainly more advanced in terms of the possibilities of electric lighting and controls, but fundamentally shares this focus on the electric lighting system as separate from the fenestration and does not develop a comprehensive, up-to-date research agenda to achieve truly integrated daylighting and electric lighting systems. As a sign of the continued relevance and importance of achieving this integration, the International Energy Agency's Solar and Heating Cooling Program is coordinating a research project on "Integrated Solutions for Daylight and Electric lighting", with results originally (i.e., prior to the ongoing coronavirus pandemic) scheduled to be available in 2021.

The work presented here identifies the discordant context of today's ecosystem of daylighting and electric lighting systems research, design, implementation, and operation, and attempts to define a research agenda to achieve truly integrated daylighting and electric lighting systems. The work presented here has two primary sections: the first (Sections 3.1 and 4.1) characterizes the current state of professional practices, continuing education, and standards used in the architecture-engineering-construction (AEC) industry, and their future research needs. The second (Sections 3.2-3.5 and 4.2, Sections 4.3-4.5) describes the state of research for both daylight and electric lighting systems as well as future research needs.

\section{Methods}

A variety of methods was used to extract and develop the relevant information about the institutional barriers to lighting systems integration, impacts on occupants, and hardware and software issues. First, a series of informal discussions were conducted with a cross-section of architecture, engineering, construction, and development industry professionals (AEC) to discern the primary issues with the design, construction, operation, and maintenance of integrated lighting systems from the practitioner's perspective. The discussions followed a loose framework of subjects and questions based on literature reviewed for the scoping study as well as previous discussion topics.

An assessment of literature in the glare, day- and electric lighting systems area was conducted at several levels of detail. A meta-analysis of 453 academic papers, books, guidelines, standards, and conference proceedings was conducted. Of those papers, 78 were read to understand specific types of research being conducted in the area of lighting, daylighting, and glare, and were used to guide discussions with AEC professionals. This assessment was not intended to be a comprehensive review of the whole field, nor was it intended to be a formal literature review.

The voluntary standards evaluation focused on the U.S. Green Building Council Leadership in Energy and Environmental Design (LEED), because this is the most used voluntary standard in the world. More than 450 projects were evaluated to understand the degree to which projects across all certification levels were receiving credits for lighting systems (daylight and electric lights) and to what degree those projects were able to integrate those systems with each other-and other building mechanical, electrical, or plumbing systems. The version 3.0 LEED 2009 for New Construction (NC) was chosen for the number of projects certified, and the simplicity of the NC category. The information used to evaluate the LEED projects was extracted from their website using two methods: (1) a download of the publicly available information for the entirety of the LEED projects database in the form of a spreadsheet; and (2) the extraction of a more comprehensive subset of data (also publicly available) for more than one hundred projects in each of the four LEED certification categories (Certified, Silver, Gold, and Platinum), using a simple web scraping script. 
The methods used to evaluate case studies used existing case study frameworks as a guide. The following case study outlines and methods were reviewed: the General Services Administration's Sustainable Facilities Tool [13], The National Institute of Building Sciences' 'Outcome-Based Pathways for Achieving Energy Performance Goals' [14] the 'Whole Building Design Guide' [15], the New Buildings Institute's 'Outcome-Based Energy Codes' [16], and the Energy-Performance-Based Acquisition for Commercial Buildings [17] processes. These publicly available case studies, building evaluation methods, and design tools were used to formulate recommendations specific to integrated lighting studies, but complementary to the body of work already in use to document exceptional buildings.

Defining the state of the art of the technology was achieved through informal discussions and brainstorming sessions with selected domain experts including electric lighting systems, controls, daylighting systems, and lighting simulation. This also helped define an initial list of possible research gaps. This information was refined and prioritized in a workshop that involved representatives of several stakeholder communities, including architects, engineers, manufacturers, building owners/operators, academics, government researchers, software developers, and educators. Section 4 of this paper presents more details on this process.

\section{State of the Practice and Technology}

The scoping study comprehensively charted the scope, range, and type of current methods of design and construction practices, the research and development of integrated lighting systems, their essential elements, and the dynamics that influence the design, implementation, and operation of those systems. The goal, ultimately, is to inform AEC industry best practices, research policy, and research and development programs. Professional development and research needs for industry practice and research programs were identified in the scoping study. The process included the evaluation of current literature, standards and guidelines, informal conversations with stakeholders, and workshops. Overall R\&D priorities, multi-stakeholder needs, and research interdependencies were refined during a stakeholder workshop at the completion of the scoping study. Each section of the scoping study concludes with stakeholder prioritized recommendations for future research, professional and continuing education, and standards.

\subsection{Institutional Barriers Preventing Lighting Systems Integration}

The scoping study exposed gaps in professional knowledge and skills regarding the proper design of lighting systems (inclusive of electric light, daylight, and solar control) within the AEC community. These knowledge and skills gaps are persistent and wide. As the realization of high-performance design goals (necessitated by more rigorous design standards and building codes) becomes increasingly complex, these gaps are widening. Simulation requirements are becoming more detailed and time-intensive, hardware and software interactions are convoluted by a mix of proprietary systems, code requirements are labyrinthine, design team organization is cumbersome, budgets for design are shrinking, while at the same time the timelines for construction are shortening and costs are rising. These circumstances make overcoming systemic inertia abstruse when viewed through the frame of reference of a single profession or building system.

3.1.1. Institutional and Organizational Inertia Working against Integration of the Day- and Electric Lighting Systems

The AEC ecosystem is dissatisfied by the necessity of doing more with less, while simultaneously navigating system performance and cost ambiguities. Well-intentioned design teams are perplexed by the inability to acquire performance information about their designs because of persistent questions about software validation, the patchwork nature of standards, codes, and guidelines, the absence of transparency between professions and industries, and the inconsistent commissioning of completed projects. Industry conditions currently make the integration of day- and electric lighting systems arduous in new buildings, and effectively impossible in existing buildings. AEC practitioners recommend the 
separation of daylight and electric light systems due to proprietary, incompatible, control technologies with little standardization. Despite the desire of the AEC industry to have integrated lighting systems, current best practices encourage segregating lighting and shading controls in new buildings (and are a practical necessity for existing buildings). Each of these concerns are real but are not consistent across all projects for all teams. Professionals across the AEC ecosystem are enthusiastic for higher performance and fully integrated building systems. There are, however, meaningful barriers to achieving this integration.

\subsubsection{Summary of Current Glare, Electric Lighting, and Daylighting Systems Literature}

An evaluation of glare, day- and electric lighting systems literature was conducted. Although more than 450 papers were evaluated, the assessment was not intended as a comprehensive review of the field, or a traditional literature review. The quality and quantity of research being undertaken at National Laboratories, in higher education, and industry is noteworthy; however, the dissemination and penetration of this research into AEC industry best practices is hampered by the current dissemination pathways which have a narrowly focused audience. Each stakeholder group focuses research and dissemination within its network. This process is understandable, but reaching audiences outside distinct industry networks will necessarily be constrained.

\subsubsection{Voluntary Standards Review}

The scoping study reviewed only one voluntary standard-the U.S. Green Building Council's Leadership in Energy and Environmental Design (LEED). The purpose for evaluating only one voluntary standard was to avoid being bogged down by the discussion of voluntary standards, guidelines and certification programs [18-21]. This section was conducted without a detailed assessment of building and zoning codes, because there are sources of inclusive information pertaining to the comprehensive appraisal of the various design, construction, and operations codes, standards, and guidelines. Significantly, there is no national building code for the United States, and, as a result, there is an arbitrary arrangement of codes across the country. This review was intended to evaluate LEED for its coordination of building lighting systems in general, and to understand the degree to which buildings designed with voluntary performance standards reward the integration of lighting systems [22-27]. LEED was chosen because it is the most widely used voluntary rating system in the world [18].

\subsubsection{Critical Information to Lighting Systems Integration Case Studies}

Case studies are used both for evaluating internal team processes as well for external professional education tools. Existing case study frameworks were evaluated for improvements to case studies that explicitly highlight lighting systems integration [13-17]. Case studies are of fundamental importance to the AEC professions. Information assembled from project records is valuable for disseminating the degree to which industry best practices are successful, or not, in achieving the goals and objectives of a given project. Case studies are also valuable in understanding how research outcomes affect the performance of buildings. Current case study frameworks form a solid foundation. There are, however, additional elements that could deliver better depth and understanding of lighting systems integration. The establishment of case study criteria inclusive of design and performance metrics, team organization and process infographics, and contract examples would be particularly helpful to understand the successful integration of lighting systems with each other as well with other building systems. Finally, connected lighting systems create streams of data with the potential to greatly expand the understanding of lighting integration projects.

\subsection{Visual Comfort in Buildings}

Glare is defined by the International Commission on Illumination (CIE) as a phenomenon that is caused by unsuitable luminance in the field of view, either from a range of 
luminance sources that is too broad or from an uneven distribution which creates extreme contrasts. Such luminance patterns can cause discomfort or can reduce the ability to see details or objects. Discomfort glare is further defined by the CIE as "glare that causes discomfort without necessarily impairing the vision of objects [28]". Discomfort glare thus describes a subjective sensation (discomfort from glare) that may or may not impair visual performance (disability from glare).

For integrated daylight/electric lighting system considerations, discomfort glare from any of the sources of illumination is an important concern. Discomfort glare from daylight sources often causes the building occupant to close window blinds, thereby reducing the energy savings that result from dimming the electric luminaires. Manually operated blinds may remain closed even when glare is no longer present, further diminishing energy savings and restricting the other positive benefits of daylighting and views. Glare from electric lighting is worst when the systems operate at their full output; if the window blinds are closed, the output of electric lighting increases, which, in turn, makes glare from luminaires more likely. Luminaire glare can create ergonomic issues for the occupant, who may alter their normal seating position and viewing directions in response to the glare.

The human visual system is able to adapt over time to a wide range of luminance levels, through changes in pupil size and through slower changes in the sensitivity of the rod and cone photoreceptors. Adaptation takes time; therefore, the visual system can adapt to only a limited range of luminance at any given point in time. If the luminance range is too great, regions of the scene that are of excessively high luminance can lead to discomfort. Common examples of such situations include the headlights of oncoming vehicles when driving after dark and direct sunlight through windows in daytime.

Discomfort from glare is not well understood. Despite the existence of many experimental studies of discomfort from glare in various contexts, there is still no agreed model for predicting the likely presence and severity of discomfort. Furthermore, the metrics used for characterizing discomfort glare differ for daylight sources and electric lighting sources, and the methods used for measuring both the glare-causing stimulus and the human responses vary widely. As a result, the reliability of the metrics in predicting human responses to glare, whether from daylight, electric light, or a combination of those sources, remains an open question. This section reviews these topics; Section 4.2 outlines possible research needs related to discomfort glare in buildings.

\subsubsection{Metrics for Discomfort Glare}

Metrics for discomfort glare are often based on a determination of the contrast between the luminance of the glare source and the luminance of the background to the glare source. The metrics also typically account for the size of the source(s), the location of the source(s), and the number of sources. Within those broad descriptions, however, there are many different expressions that have been used historically for computing metrics of discomfort glare.

Of the glare metrics shown, the industry has mostly settled on using the Daylight Glare Probability (DGP) metric for glare from daylight and the Unified Glare Rating (UGR) metric for glare from electric light sources. Metrics for glare from electric lighting were reviewed by Eble-Hankins and Waters, and Ashdown [29,30]; van den Wymelenberg [31] and Wienold et al. [32] provided reviews for metrics related to glare from daylight. Both of these metrics considered the luminance of the luminaires or windows serving as the potential glare sources, the sizes of the glare sources, the position of the glare sources with respect to the direction of view, and the background luminance that affected the adaptation level of the viewer. Their specific derivations and mathematical constructions are shown in the cited papers, and were developed to best match empirical data on the levels of discomfort. The UGR has a value between 5 and 40, with a higher value meaning more glare. The DGP has a value between 0 and 1, with a higher number meaning more glare. Importantly, none of the glare metrics account for the spectral power distribution of the glare sources. 


\subsubsection{Test Procedures for Discomfort Glare Research}

Experimental designs for studying discomfort glare can be categorized by whether the subject has an external reference for comparison (i.e., absolute measurement or measurement with respect to a second relevant scene), and whether the subject is a passive or an active participant in the experiment, in terms of direct control of the stimulus conditions [33]. Fotios and Kent reported four possible approaches and detailed the measurement issues involved in each approach, as summarized below.

Category Rating procedures occur when there is no external reference, and the subject has no direct control over the stimulus. This procedure usually involves a single interval task in which the participant rates the degree of discomfort experienced when observing a visual scene by allocating it to a category such as "imperceptible" or "intolerable." The number of response points and the labels of each category vary between studies. In category rating discomfort glare studies, different visual scenes are typically presented and evaluated individually, in succession. Potential experimental biases introduced by the category rating method include stimulus range bias, pre-trial demonstration, order effects, and response scale design (including the number of response categories, number of rating items, category labels, language translation, and common understanding). In addition, statistical analyses of category rating data must address whether parametric or non-parametric statistics are appropriate.

Discrimination procedures occur when passive subjects judge scenes with an external reference present. The participant reports which of two scenes presents the greater degree of discomfort; this method is also known as paired comparison. The two scenes are presented side-by-side or in sequence, and the conditions of both scenes are fixed for a given trial. Discrimination has rarely been used in discomfort studies.

Matching procedure also presents active participants with two scenes. One scene is the reference and remains unchanged. Participants are instructed to vary the glare source luminance of the second (test) scene until it matches as near as possible the degree of discomfort portrayed by the reference scene. Matching has rarely been used in discomfort studies.

Adjustment methods involve an active participant observing only a single visual scene; judgements are made against an internal (memory) reference. The luminance of the glare source in the scene being judged is adjusted by the observer until the level of discomfort reaches a specified level. This method has been used in past studies to define the borderline between comfort and discomfort (BCD). Potential experimental biases introduced by the adjustment method include stimulus range bias, anchor effects, order effects, direct versus indirect control, visual tasks, and effect sizes of different factors.

In addition to the subjective psychophysical approaches that have been common in discomfort glare research, advances in various physiological and other measurement techniques show promise for documenting the effect of glare sources on humans $[32,33]$. Fotios and Kent provide a summary of past studies that have measured discomfort using methods other than subjective psychophysical procedures [34]. Such methods include measuring changes in pupil size, electrograms using techniques such as electromyography (EMG), extent of eye opening, brain activity such as that measured through functional magnetic resonance imaging (fMRI), gaze behavior, and behavioral responses such as closing window blinds or changing seating positions and view direction.

\subsubsection{Measurement of Glare Conditions}

Discomfort glare is fundamentally an issue of luminance contrasts. Consequently, characterizing the stimulus conditions that may create discomfort depends on measuring luminance in realistic settings. Historically, these measurements have been conducted using hand-held "spot" luminance meters to capture the luminance values of multiple points within the field of view. A full characterization of the elements of the field of view that may contribute to glare requires many measurements, and the accuracy of each measurement depends on careful aiming and focusing of the luminance meter; therefore, 
data collection is very labor intensive. As a result, many of the past studies on glare had limited characterizations of the luminance distributions within the space of interest.

More recently, high dynamic range imaging (HDRI) devices have been used for luminance measurements in architectural applications. For example, the development and initial evaluations of the Daylight Glare Probability (DGP) metric were based on images using a scientific-grade CCD camera [35]. Since 2010, other researchers have used luminance data derived from HDRI using commercial cameras for glare evaluations and the development of potential new metrics for glare [31,36-40].

Many remaining questions about how to identify and measure the luminance of the glare source(s) and of the background to the glare source(s) are still unresolved. Furthermore, the sources and magnitude of errors in luminance measurement through HDRI are an active current topic of research [41].

\subsection{Non-Visual Effects of Lighting and Possible Impacts on Human Health}

Research exploring human physiological responses to light and continued advances in SSL technology have aligned with an increasing demand for healthier buildings by building owners and occupants, including greater access to daylighting. Interest in WELL ${ }^{\mathrm{TM}}$ [42] certified spaces, where the wellness of building occupants is the primary focus of architectural design, has increased rapidly in the past few years. The renewed focus on health has emphasized that there is still much to learn regarding the relationship between light and human physiology, including the energy implications of designs which address these possible physiological effects. The common metric of luminous efficacy (lumens per watt) does not apply to light's stimulation of non-visual physiological effects, and the emerging science seems to indicate that designing lighting for these non-visual effects may mean a need for increased light exposure. This increase in light has an associated increase in energy use if it is met only by electric lighting systems. Consequently, the energy use intensity for lighting may exceed levels predicted by luminous flux-based analyses for traditional applications which are based solely on visual task performance.

\subsubsection{Metrics for Non-Visual Effects of Light}

Although the full relationship between light and human biological functioning is not fully understood, several techniques have emerged to estimate the possible relative effects of different light sources based on their spectral content, usually characterized as the spectral power distribution (SPD). For example, the equivalent melanopic lux (EML) metric was derived from a journal paper and spreadsheet tool box published by Lucas et al. [43]. This method determines the EML by weighting the SPD of the light source by the spectral efficiency function of the photoreceptors that have the most direct influence on non-visual effects of light, the intrinsically photosensitive retinal ganglion cells (ipRGCs).

The EML metric defined by Lucas et al. is not compliant with the International System of Units (SI). As a result, the International Commission on Illumination (CIE) approved an alternate, SI-compliant method for evaluating melanopic content, defining the spectral sensitivity functions for each of the five photoreceptors that can contribute to non-visual responses (i.e., three types of cones, rods, and ipRGCs). CIE also adopted an alternative metric for melanopic responses, referred to as melanopic equivalent daylight illuminance (melanopic EDI) [44]. Melanopic EDI is based on the D65 daylight reference source rather than the equal energy source used in the derivation of EML. CIE subsequently published a position paper recommending that melanopsin-based photoreception may be manipulated as a strategy for managing input into ipRGC-mediated non-visual responses, and explaining that consensus recommendations for specific levels of melanopic EDI to produce desirable responses have not yet been established [45].

The EML and melanopic EDI metrics are based solely on the ipRGC response without including separate contributions from other photoreceptors. Rea and Figueiro [46-48] proposed an alternative metric, circadian stimulus (CS). The CS metric was designed to be proportional to the suppression of nocturnal melatonin production; the underlying math 
considers the spectral composition of light at the eye as weighted by relative contributions of all five photoreceptor types (ipRGCs, rods, and three types of cones), in part by incorporating the blue-yellow (b-y) opponent processing mechanisms. This technique for including the possible role of all photoreceptors in melatonin suppression had not been widely accepted by the medical community at the time of this paper.

Analytic tools are readily available for calculating the EML, melanopic EDI, and CS values for a given SPD and illuminance at the eye. However, to implement these new metrics, target criteria are needed for different applications and desired outcomes. Establishing criteria for non-visual goals is complicated because our understanding of these processes is still emerging, as Lucas explains [43]:

"Although melanopsin phototransduction is only engaged at moderate to high irradiance, ipRGCs and their downstream responses can be responsive to much lower levels of illumination. For example, it was originally thought that illuminance of 2500 lux was required to suppress nocturnal melatonin in humans [49], but later studies have shown that under certain conditions, as little as 1 lux or less can suppress melatonin in humans [50]."

\subsubsection{Recommendations for Practice}

Recommendations for appropriate levels of EML, melanopic EDI, or CS have not been adopted by a recognized industry standards organization. However, there are currently two primary organizations with documents that recommend methods for designing lighting to account for the human non-visual system: The International WELL Building Institute ${ }^{\mathrm{TM}}$ (IWBI ${ }^{\mathrm{TM}}$ ) and Underwriters Laboratory (UL). The IWBI maintains WELL, also known as The WELL Building Standard ${ }^{\mathrm{TM}}$. The 2021 version of WELL v2 includes recommended levels of EML and m-EDI in its criteria. UL 24480, "Recommended Practice and Design Guideline for Promoting Circadian Entrainment with Light for Day-Active People" is solely focused on circadian-effective lighting. The document describes how circadian-effective lighting designs are accomplished and verified, based on the circadian stimulus (CS) metric. Brown et al. published recommendations for healthy daytime, evening, and nighttime indoor light exposure, indicating a minimum of $250 \mathrm{~m}$-EDI at eye level throughout daytime as desirable [51]. No authoritative consensus-based standards body, including the Illuminating Engineering Society (IES) and International Commission on Illumination (CIE), has approved recommended levels for any of these metrics. Despite the uncertainty and lack of consensus, these metrics are continuing to gain increasing attention in lighting, healthcare, and education industries.

\subsubsection{Software Tools}

Widely used lighting software programs, such as AGi32 and Radiance, rely on simplifying assumptions about surfaces and light sources, including assumptions about their spectral properties. AGi32 is commercial software with a user-friendly interface but it does not account for any spectral properties of the light source or the surface reflectance. Radiance is open-source software that lacks a user-friendly graphical user interface and that considers a simple three-channel (usually in RGB) spectral model for light sources and surfaces; these three channels provide roughly $130 \mathrm{~nm}$ of spectral resolution. The growing interest in designing spaces that consider the human non-visual responses to light combined with the emergence of spectrally tunable SSL systems as a design strategy has motivated the development of software tools capable of predicting both the intensity and spectrum of light at the eye, with greater spectral resolution possibly needed to account for the narrow band nature of SSL sources and of the different human response functions of interest. Accounting for the spectral interaction of light with objects and materials in the built environment requires complex computations, especially as tunable LED lighting systems, sky conditions, and dynamic façade elements provide more dynamic variation of the spectrum of light in an environment. 
Common practices for calculating non-visual metrics include simulating or measuring the photopic illuminance at the eye and then using the rated SPD of the luminaire to calculate EML, m-EDI or CS. Valuable information pertaining to the architectural surface reflectance, furnishings, and the combined contributions from day and electric light sources is not considered when using this method. There can be a significant difference between the SPD of the luminaires and the SPD measured vertically at the eye when these sources of variation are considered.

One new software tool capable of such computations is Adaptive Lighting for Alertness (ALFA), commercially available through Solemma, LLC. ALFA is built on the Radiance calculation engine but improves upon it, by considering SRDs for all surfaces and SPDs for all light sources, both of which are discretized into 81 channels across the visible spectrum. ALFA enables analyses of daylighting and electric lighting sources. Another tool with spectral modeling capabilities is the open-source Lark program, originally developed for daylighting analysis as a collaboration between ZGF Architects and the University of Washington. Lark also uses the Radiance calculation engine but adds the capability to model nine spectral channels as well as the normal three-channel Radiance models. Although designers and researchers are using these new tools for lighting simulations, the software tools have not yet been fully validated, and the developers have not yet included the many additional variables introduced by integrated building façades and daylighting, in some cases because the desired resolutions of spectral data are not available.

\subsubsection{Energy Consequences of Non-Visual Effects of Light}

The energy consequences associated with meeting the current recommendations for EML, m-EDI and CS are not addressed by WELLv2 or UL RP 24480. Previous GATEWAY field evaluations [52-54] found that current IES illuminance recommendations based on visual tasks are too low to meet WELL and UL non-visual recommendations. Safranek et al. [55] reported simulations of electric lighting which also demonstrated that meeting current IES illuminance recommendations did not satisfy current non-visual recommendations. For some simulations that did meet non-visual metric recommendations, average illuminance was more than double the IES recommendations along with high CCTs, beyond what is typically considered acceptable for office settings. Only one set of parameters for the office simulations (6200 K CCT luminaires with horizontal illuminance of over $800 \mathrm{~lx}$ and high reflectance room and desk surfaces) was able to meet the WELL v2 requirement of EML $\geq 240$ at all seated view positions to earn three points (2019 Q2 Circadian Lighting Design feature). This simulation condition increased energy use by $30 \%$ even at the minimum suggested duration of $4 \mathrm{~h}$ per day for the high EML lighting.

The variables considered for the simulations were limited to specifically compare the intensity and SPD of electric light in the built environment. Additional variables, such as those discussed as the related research needs (Section 3.3), have not yet been considered in detail. However, it seems clear that the emerging demands for higher intensities of light in buildings may significantly affect the energy-saving possibilities of SSL lighting systems if those systems alone must meet the new requirements.

\subsection{Integration of Hardware and Controls for Day-and Electric Lighting Systems}

Daylighting and electric lighting systems consist of concrete physical hardware that operates in buildings. A fundamental aspect of integrating these systems is the integration of their hardware and, for active systems, also the way they are controlled, with the ultimate goal of this hardware functioning and acting as a single system for providing light to the building's occupants.

The first challenge stems from the fact that, with rare exceptions [56,57], façade and lighting systems are completely separate-different manufacturers, separate control infrastructure, software, and user interfaces. The result of this is that, in the overwhelming majority of cases, interactions between the two types of systems are mediated through their effects on the building and not through direct communication between systems. 
This mediation is imperfect and can cause less than optimal performance. For example, a change in the angle of a venetian blind will often have an impact on the distribution of light within a space. The electric lighting system will sense this change remotely, through photosensors usually placed on or near the ceiling. However, this single signal lacks information which is needed for the lighting system to respond optimally; a change in photosensor signal could have many other causes that would require different responses, such as a change in the overall reflectance of the environment (no response needed), a change in the amount of light reflected onto the sensor without a corresponding change on the horizontal work plane (possibly no response needed), or a true change in the horizontal illuminance of the space (change in electric light levels probably needed) [58].

Although the lack of direct communication between façade and lighting systems remains the norm, many lighting and façade systems have the technical capability to communicate with other building systems via generic communication protocols, such as BACnet. However, even if this capability can be used in particular cases to integrate lighting and façade systems, implementing and maintaining a solution that provides energy efficiency and occupant comfort often requires significant effort by specialized personnel and coordination between different entities, making this option challenging for many, if not most buildings [57].

Although the challenges above are mainly concerned with maintaining adequate light levels, the spectrum of light provided to a space is increasingly relevant. Façade and lighting systems often rely on photosensors, but these are commonly focused on detecting photopic light levels., i.e., they do not provide information on the spectral content of light. Although instruments certainly exist to characterize such content, they are only beginning to be available in the combination of price and performance needed for cost-effective and widespread deployment in buildings [59].

\subsection{Simulation and Software for Integration of Day-and Electric Lighting Systems}

Many different software packages are available for computing the distribution of electric lighting and daylight throughout the built environment. They range from simpleto-use early design tools [60] to powerful tools that can achieve a great degree of accuracy when used by highly trained specialists [61,62]. Some tools [63] offer a combination of both, through providing relatively simple-to-use graphical user interfaces to powerful tools such as Radiance [63]. Others, such as SPOT [64], a tool to aid in the placement of photosensors for lighting control systems, are targeted at very specific tasks. Although this is an impressive assortment of tools that, in the hands of experts, could be-and has been-used to design and evaluate integrated façade and electric lighting systems [65], there are currently no tools specifically aimed at enabling such integration for a wider user base.

Simulation tools for lighting designs in buildings usually compute photopic lighting quantities or divide the computation into three channels: red, green, and blue. Although this is appropriate for the vision function of lighting, it is not so for the non-visual effects of lighting. Emerging tools address this by dividing the visible spectrum into a higher number of channels, up to $81[66,67]$. Although these tools can build on existing lighting simulation engines, experimental validation of their accuracy for computing the non-visual effects of lighting has not been performed to the same extent as the validation of tools for computing photopic quantities.

Another challenge for modeling spaces with these tools outside of a research context is that some of the data inputs which are needed are not available-at least for the majority of potential users-at the necessary spectral resolution.

\section{Research Needs}

In September of 2020, a workshop was convened for the purpose of vetting the Integration of Daylighting and Electric Lighting scoping study findings. The workshop was hosted by the Lawrence Berkeley National Laboratory. There were 32 total participants, 
including organizers/speakers, most of whom were able to participate for the full event. The participants engaged in a two-hour web-based workshop to complete the initial stakeholder prioritization of professional and continuing education, standards, and research and development topics. There were three breakout groups, matching with the three primary topics of the scoping study-institutional barriers to lighting system integration, impacts on occupants, and hardware and software issues. Those breakout sessions discussed and prioritized the research topics that were identified during the scoping study. Below is the top level of stakeholder priorities, with detailed descriptions following. A summary of the research priorities identified is shown in Table 1.

Table 1. Research topics identified as priorities for achieving deeper integration between electric lighting and daylighting systems.

\begin{tabular}{|c|c|c|}
\hline Categories & Top Priorities & Additional Important Priorities \\
\hline Institutional inertia & $\begin{array}{l}\text { - Development of better models for return } \\
\text { on investment and simple payback for } \\
\text { advanced lighting control systems } \\
\text { - Validation of non-energy benefits }\end{array}$ & \\
\hline Scientific literature & $\begin{array}{l}\text { - Develop a standard for what constitutes } \\
\text { a minimally acceptable number of human } \\
\text { subjects for reliable results } \\
\text { - Verify leading edge work is consistently } \\
\text { and appropriately targeting specific impact } \\
\text { (e.g., applied R\&D) }\end{array}$ & $\begin{array}{l}\text { - Publication and/or dissemination plans } \\
\text { to ensure the target audience is reached }\end{array}$ \\
\hline Voluntary standards & $\begin{array}{l}\text { - Motivations of project owners for } \\
\text { integration of day- and electric light } \\
\text { systems } \\
\text { - Partnerships for increasing market } \\
\text { penetration of controllable systems }\end{array}$ & $\begin{array}{l}\text { - Evaluation of role of controllable systems } \\
\text { in the design process }\end{array}$ \\
\hline $\begin{array}{l}\text { Lighting systems integration case } \\
\text { studies }\end{array}$ & $\begin{array}{l}\text { - Cost effectiveness, functional project, and } \\
\text { productivity goals, and influences of } \\
\text { lighting integration on the outcomes of } \\
\text { these goals } \\
\text { - Construction, operations and } \\
\text { maintenance (O\&M), and post-occupancy } \\
\text { evaluation (POE) activities that directly } \\
\text { apply to the integration of lighting systems } \\
\text { into the project }\end{array}$ & \\
\hline Visual comfort in buildings & $\begin{array}{l}\text { - Exploring relationships between } \\
\text { physiological measures of occupant } \\
\text { responses and psychophysical measures of } \\
\text { discomfort } \\
\text { - View direction and motivations and the } \\
\text { effect of glare tolerance }\end{array}$ & $\begin{array}{l}\text { - Experimental research to assess the } \\
\text { alignment of the current metrics (DGP, } \\
\text { UGR) with human responses to glare } \\
\text { - Validation studies of measurement and } \\
\text { simulation tools used to determine glare } \\
\text { metrics } \\
\text { - Research towards a new glare metric } \\
\text { based on human visual science that } \\
\text { addresses discomfort from daylight and } \\
\text { electric lighting systems in complex scenes } \\
\text { - Exploring and delineating test } \\
\text { procedures and methods that are suited for } \\
\text { integrated daylight and electric lighting } \\
\text { scenarios }\end{array}$ \\
\hline Non-visual effects of lighting and impacts on human health & $\begin{array}{l}\text { - Improved tools that enable the } \\
\text { simulation of the important parameters for } \\
\text { non-visual effects } \\
\text { - Daily patterns of view directions and } \\
\text { light stimulus exposure for different } \\
\text { populations of building occupants in } \\
\text { different types of building applications }\end{array}$ & $\begin{array}{l}\text { - Improved tools for combining electric } \\
\text { light and daylight contributions } \\
\text { - Considering a wide range of luminaires } \\
\text { with different form factors and color } \\
\text { mixing strategies from different } \\
\text { manufacturers in non-visual metric } \\
\text { research } \\
\text { - Wider consideration of building types } \\
\text { - Wider access to spectral modeling tools }\end{array}$ \\
\hline Integration of hardware and controls & $\begin{array}{l}\text { - Demonstrating the value and non-energy } \\
\text { benefits of integrated systems } \\
\text { - Developing spectral power distribution } \\
\text { sensing }\end{array}$ & $\begin{array}{l}\text { - Identifying and developing appropriate } \\
\text { communications and controls methods }\end{array}$ \\
\hline Simulation and software & $\begin{array}{l}\text { - Validation of simulation tools } \\
\text { - Making available the inputs that are } \\
\text { required for simulation of non-visual } \\
\text { effects of lighting }\end{array}$ & $\begin{array}{l}\text { - Developing tools for integrating } \\
\text { photosensors into lighting/daylighting } \\
\text { systems } \\
\text { - Determining the optimum wavelength } \\
\text { resolution for simulation of non-visual } \\
\text { effects of lighting } \\
\text { - Implementation in simulation software } \\
\text { of control algorithms }\end{array}$ \\
\hline
\end{tabular}


Many of the issues discussed during the workshop are issues that have been persistent across each of the separate primary topical divisions. Institutional barriers have consistently included questions of returns on investment and the financial impacts of new technologies; visual comfort has been a long-term topic of research for understanding the impacts on occupants; and hardware and software issues have had to continually address validation requirements. What has changed is the depth to which each of those issues has been addressed, or the extent to which new variables have been added to the research, development, and application of lighting systems. What is important is seeing the linkages between the topical divisions - both the institutional barriers and the hardware and software areas see the validation of the non-energy impacts of lighting system integration as critical to understand moving forward. When this is connected with the impact on occupants from developing a greater understanding of view directions in buildings (and motivations for those view directions), how those motivations might affect tolerance for visual discomfort, and the unsettled science on the basic human physiological responses to light, it becomes apparent that the non-energy impacts of daylighting and electric lighting systems are on the critical path to their integration.

\subsection{Institutional Barriers Preventing Lighting Systems Integration}

Each of the institutional barriers had several subcategories of investigation. During early stakeholder discussions, a set of preferences and priorities began to come into focus. In order to limit the scope of this paper, the discussion will be limited to those areas with the greatest interest from those stakeholder discussions. The breakout groups that discussed the topics of (1) Institutional and organizational inertia working against integration of day- and electric lighting systems; (2) Summary of Current of Glare, Electric Lighting, and Daylighting Systems Literature; (3) Voluntary Standards Review; and (4) Critical information to lighting systems integration case studies came to the following conclusions.

4.1.1. Institutional and Organizational Inertia Working against Integration of the Day- and Electric Lighting Systems

The top two areas of professional and continuing education, and standards research and development needs for Institutional and organizational inertia working against integration of day- and electric lighting systems include:

1. Development of better models for return on investment and simple payback for Advanced Lighting Control Systems. This was chosen as the primary need because there is relatively little baseline understanding of how people are using manual daylighting systems, and there is a real need to be precise about what the integration of day- and electric lighting systems means, and how their integration is quantified. This topic was seen to have a short timeline for completion of the necessary research (1-2 years), but is heavily dependent on having the infrastructure in place to establish accurate return on investment (ROI)/simple payback (SPB) results. Although this need had near-unanimous support within the breakout group, there was little discussion about the details of what should be undertaken in the development of the research;

2. Validation of non-energy benefits was determined to be the second highest priority. There was much discussion within the breakout group and in the full group about the non-energy benefits associated with integrated lighting systems. Understanding all impacts (benefits and drawbacks), with agreement among stakeholders, is necessary, because there needs to be improved understanding of the objective benefits of non-energy financial implications. The group felt that non-energy benefits of lighting systems integration can be very hard to monetize but are reasonably well characterized. Although these benefits can be harder to quantify, monetization is necessary if they are to be used in ROI or SPB calculations. Being able to accurately value the non-energy benefits is useful during financial decision-making, because there is potential for significant value. There was discussion about the degree to which all non-energy benefits need to be quantified or monetized-developers make decisions 
beyond ROI, and understand other motivations. The non-energy benefits need to be validated/verified, but not necessarily monetized. For developers, market demand is a substantial driver, where decisions are made on factors beyond simple dollar amounts. However, those decisions are still made on tangible data. Two additional observations were made by the group about the non-energy benefits of integrated lighting systems. The first is that it can be hard to connect sincere interest in daylighting with actual implementation; therefore, having lighting systems goals/targets that were connected to tangible benefits would be helpful. In addition, resiliency is becoming increasingly important, and lighting systems that are resilient are becoming increasingly essential to public health and safety needs. This task was seen as having a longer timeline for the completion of research and development of standards, in the medium term ( $2-5$ years).

Although consensus was clear regarding the top two research priorities, there were other areas where the group thought the need for better understanding of the topic was warranted.

- Develop commissioning (Cx) standards for daylighting systems and $\mathrm{Cx}$ agents was thought to be a valuable research priority. The group felt that it is a true pain point for building owners and operators, as well as design and construction teams. Development of an efficient $C x$ performance methodology, with consistency of application, and at lower cost, would be tremendously helpful to the industry. The group concurred with the idea that in order for daylight systems (and integrated systems) to achieve lower ROIs, proper $\mathrm{Cx}$ is a necessity. A fundamental part of understanding how people use manual daylighting systems is important from a modeling standpoint, and therefore for system Cx. The industry does not yet have good models of the baseline manual operation of window management systems; therefore, more rigorous population studies of user behavior are needed. This task was seeing as having a short-term (2 years) timeline for the development of Cx standards and education for Cx agents.

\subsubsection{Summary of Current Glare, Electric Lighting, and Daylighting Systems Literature}

The top two areas of professional and continuing education, and standards research and development needs for Summary of Current Literature include:

1. Develop a standard for what constitutes a minimally acceptable number of human subjects for reliable results. The larger group indicated that this area may be resolved at the basic research level; however, it is also possible that it has not been effectively disseminated to stakeholders outside this basic research level. It was observed by the larger group that the number of subjects is significantly dependent on methodology, and perhaps this question is more important than understanding an absolute number of how many human subjects are involved in any particular research project. Even though the larger group understood that this issue is near resolution in the basic research community, members of the breakout group felt it was still the top issue in the larger question of the dissemination of research findings between and within stakeholder groups. A broader question about the credibility of any given research project and the results from that research is an important one. The LEUKOS Special Issue on Lighting Research Methods offers useful insights [68]. With respect to sample size, in particular, see Uttley [69]. The breakout group felt that the timeline for this priority was short-term (2 years);

2. The breakout group felt that the Verify leading edge work is consistently and appropriately targeting specific impact (e.g., applied R\&D) was the next most important priority, noting that the synthesis of case studies is absolutely essential for the AEC industry. Having a continuously updated stream of case studies can help to verify that the research reaches its intended audience and the built environment. The breakout group felt that the timeline for this priority was short-term (2 years). 
Aside from the top two priorities, the group agreed that dissemination is key for information and technology transfer, and it is in need of better attention and shepherding from research to application. They were supportive of creating publication and/or dissemination plans to ensure the target audience is reached. The breakout group felt that the timeline for this priority was short-term (2 years).

\subsubsection{Voluntary Standards Review}

The top two areas of professional and continuing education, and standards research and development needs for Voluntary Standards Review include:

1. Motivations of project owners for integration of day- and electric light systems was the consensus top choice for the breakout group. Performance-based standards are critical to owners to understand the applicability of any particular technology or systems to their projects. Improvement in performance-based standards (or codes and guidelines) can make it easier to develop a greater understanding of what motivates project owners to include (or not) integrated systems in their projects. The breakout group felt that the timeline for this priority was short-term (2 years);

2. Partnerships for increasing the market penetration of controllable systems were the second priority for the breakout group. Development of these partnerships, although a longer-term prospect, were felt to be important to the long-term success of market penetration and implementation. Having a deeper set of partnerships could lead to better data alignment, because there are more stakeholders with the incentive to see project performance data consistently and cohesively maintained. The breakout group felt that the timeline for this priority was medium- to long-term (5-10 years).

The following areas had commentary dedicated to their topics, either in the breakout discussion or in the general discussion by the whole group:

- Evaluation of the role of controllable systems in the design process;

- Improvement of data alignment and accuracy.

\subsubsection{Critical Information to Lighting Systems Integration Case Studies}

The top two areas of professional and continuing education, and standards research and development needs for Lighting systems integration case studies include:

1. Cost effectiveness, functional project, and productivity goals, and influences of lighting integration on the outcomes of these goals. The larger group and the breakout group felt it would be good to know more about how user preferences and behaviors vary with system type, where the system types should include window attachments and controls, and electric lighting system controls. Good example case studies addressing how blinds are deployed by users could be used for reference and to help understand what would have the most impact for ensuring that a fragmented industry thinks in terms of optimal systems for occupants. The breakout group felt that the timeline for this priority was short- to medium-term ( $2-5$ years);

2. Construction, operations and maintenance (O\&M), and post-occupancy evaluation (POE) activities that directly apply to the integration of lighting systems into the project, were the second priority for the breakout group. The consensus about this topic was those case studies with specific ties between design goals, and O\&M activities that supported those goals, should be informed by system commissioning and POE in order for systems to have proper function from the beginning of operation and have occupant feedback inform the O\&M plan through various mechanisms. The breakout group felt that the timeline for this priority was medium- to long-term (5-10 years).

\subsection{Visual Comfort in Buildings}

The scoping study and workshop process identified two research areas as the highest priorities for visual comfort: 
1. Research that explores the possible relationships between physiological measures of occupant responses (e.g., pupil size, gaze direction, squint reflex, heart rate, galvanic skin response) and psychophysical measures of discomfort;

2. View direction and motivations and the effect of glare tolerance. This priority includes the idea of developing a frequency distribution of occupant behaviors in typical building applications where discomfort glare might be a concern; behaviors of interest include seating locations, gaze directions, use of window shades, etc. This was seen as an important need for the successful future of integrated façade electric lighting systems.

Other research needs identified through this process included:

- Experimental research to assess the alignment of the current metrics (DGP, UGR) with human responses to glare;

- Validation studies of measurement and simulation tools used to determine glare metrics to evaluate the sources of error in capturing the different elements of the metrics (luminance, geometry, size, etc.) and the impact of those errors on the metrics;

- Research towards a new glare metric based on human visual science that addresses discomfort from daylight and electric lighting systems in complex scenes;

- Exploring and delineating test procedures and methods that are suited for integrated daylight and electric lighting scenarios;

- Developing models for integrated lighting system controls that address energy and visual comfort.

\subsection{Non-Visual Effects of Lighting and Possible Impacts on Human Health}

For research needs on the non-visual effects of light in buildings, the topics suggested in the scoping study and workshop were framed by an understanding that there remains a great deal of unsettled science on the basic human physiological responses to light, due to the relatively recent discovery of the ipRGCs and the numerous lines of study that have evolved since that discovery. The top two research priorities identified for the non-visual effects of light were:

1. Improved tools that enable the simulation of the important parameters for nonvisual effects-intensity, spectrum, duration and timing of exposure, directionality of light. The group also recognized a need for considering precision in simulation tools and their inputs; in some cases, tolerances for higher levels of error may be more appropriate than in other situations;

2. Daily patterns of view directions and light stimulus exposure for different populations of building occupants in different types of building applications.

Research in the following topics was also suggested for optimizing the energy use of future buildings designed to meet a holistic set of human needs.

- Improved tools for combining electric light and daylight contributions. Although some current tools can model daylight and electric light simultaneously at specific points in time, the full implications of using these tools for the complex modeling of an integrated daylight-electric light system over the course of a year have not yet been explored. Daylight and integrated façades designed for better daylight delivery introduce many variables into the modeling process, especially when it is desirable to account for the full spectral effects of these variables; therefore, accounting for daylight contributions can quickly add complexity to simulation models and increase the computation time. Managing the required computation time will require some documentation of the possible errors introduced by simplifying assumptions that might be needed for faster computing. Furthermore, the current tools have not been fully validated for this type of simulation work; simulations of physical spaces where confirmatory measurements can be taken are needed;

- Considering a wide range of luminaires with different form factors and color mixing strategies from different manufacturers will provide a more comprehensive non-visual 
metric investigation. Given that many tunable luminaires are capable of full 0-100\% dimming and fine-tune color control, careful consideration of the trade-offs between the number of simulated conditions desired and the required computation time will be needed. Again, research that explores the range of errors introduced into simulations through simplifying assumptions is an important element;

- Early research on these topics has focused on office settings. To better understand the potential national energy implications on the entire U.S. building stock, a more thorough consideration of building types is needed, along with the relative importance of the non-visual effects of lighting within different building types;

- In considering the potential effects of daylighting on non-visual responses, it seems likely that certain climates will rely more on electric lighting than daylight to satisfy non-visual requirements. Full analysis of energy implications will need to address the differential effects of climate and physical location;

- Access to emerging spectral modeling tools make it possible to vary model parameters to include theoretical SPDs that may not exist in commercial products, whether electric luminaires or dynamic glazing. These simulations may help demonstrate the potential advantages and drawbacks of these theoretical SPDs that have been optimized for balancing considerations related to efficacy and non-visual metrics.

\subsection{Integration of Hardware and Controls for Day-and Electric Lighting Systems}

Stemming from these challenges, several needs for further research are readily apparent, which can be organized into several groups. The first group focuses on improving the reliability of building-mediated interaction between façade and electric lighting systems. This includes improving the ability of lighting control systems to sense the actual quantities of interest (e.g., horizontal work plane illuminance), either using remote sensors or sensors embedded into the work plane. Equally important is developing a better understanding of how façade systems, especially those that can significantly impact the intensity distribution of daylight transmitted through windows, interact with lighting control systems and their associated sensors. Low-cost and accurate sensors for the spectral power distribution (SPD) of light are needed if this capability is to be integrated in most lighting systems, and additional research is needed on the adequate number, placement, and accuracy of sensors for providing useful SPD information. As lighting control systems evolve beyond controlling the amount of light towards also controlling the SPD of light, research is needed on the characterization and in situ monitoring of how the light output and SPD of electric light sources evolve over time (with particular emphasis on solid-state light sources), as well as understanding how façade systems can affect and control the SPD of daylight admitted into a space.

The second group of research needs centers on direct communication between electric lighting and façade systems. Not only is it important to identify suitable communications methods and protocols for these systems to interact, some degree of standardization of these protocols is desirable if we are to achieve interoperability between electric lighting, façade, and sensors which is irrespective of who manufactures each component. Although enabling communications is paramount, it is just as important that systems are prepared to respond to the signals they receive from other systems and/or sensors, which suggests the need for a standard framework for façade and electric lighting control algorithms, that could include the range from simple heuristics to advanced techniques such as modelpredictive control. Given the expanding array of sensors and building systems that are able to communicate with other equipment, research is also needed on what kind of information could be beneficially exchanged between integrated façade and electric lighting systems and other types of sensors and building systems. Finally, it is desirable to not only control the operation of integrated façade and electric lighting systems, but also to monitor the adequateness of their performance over time, and opportunities should be explored for developing algorithms that help detect potential system malfunctions or maintenance needs. 
A third group of research is related to reinforcing the feasibility of integrated façade and electric lighting systems through demonstrating their value to a broad audience. The potential market for integrated systems needs to be more clearly defined and the best use cases for early adoption need to be identified. The value of these systems in terms of energy savings, cost-effectiveness, resilience, and occupant comfort and health needs to be more firmly established. The additional complexity of integrated systems also needs to be mitigated by adequate tools, techniques and training for a trouble-free installation and commissioning process.

In interactions with stakeholders, two top research priorities that appeared to emerge are:

1. Demonstrating the value and non-energy benefits of integrated systems, including market potential, practical use cases, cost-effectiveness, resilience, comfort, health and wellness, and aesthetics;

2. Developing spectral power distribution sensing (including camera-based approaches) is deemed as highly desirable for allowing integrated systems to better deliver the desired light spectrum (there was disagreement on whether matching the spectrum of daylight should be the goal), and also as an enabler to R\&D activities that involve non-visual effects of lighting.

These priorities only make sense when it is well known how integrated systems would operate in concert; identifying and developing appropriate communications and controls methods (e.g., ranging from open-loop to model-predictive control, and also including behavioral aspects regarding building occupants) should therefore be considered a research priority that enables those enumerated above.

\subsection{Simulation and Software for Integration of Day-and Electric Lighting Systems}

In order to facilitate the development, installation, and commissioning of integrated façade and electric lighting systems, three main research needs are outlined here. The first research need is to develop and make available software tools that are aimed specifically at integrating façade and electric lighting and that bridge the gap between the expert tools that are available and a wide, non-expert user base. These new tools could be as simple as extensions of existing early design tools, which would now have new features. Two additional research needs concern the simulation of non-visual effects of lighting. The first is concerned with making input data with the necessary spectral resolution widely available. Some of these data are already available. For example, an extensive global glazing database is already in existence [70], and some data are also available for opaque surface materials [71] and electric light sources. However, other necessary data are not usually freely available with that level of spectral resolution. This is the case not only for the surface reflectance of many surface finishes and for complex fenestration systems [72], but also, more importantly, for data on the luminous distribution of the sky, which are crucial for determining the spectrum of light which is transmitted by the façade into the building. The second, and last, research need is the validation of the software tools that are emerging and that enable the modeling of the non-visual effects of lighting. The most accurate conventional simulation tools have developed through many iterations of experimental validation that attest to the accuracy of their results; a similar process is needed so that we can be as confident of the accuracy of the results from these newer tools.

The top two research priorities that emerged from interactions with stakeholders are:

1. The validation of simulation tools. Although this topic could include both the validation of existing software for computing the non-visual effects of lighting, as well as developing new tools for that purpose, it appears that there is a significant need for the validation of software tools in general (i.e., including tools for computing photopic quantities, particularly in the computation of metrics for visual comfort);

2. Making available the inputs that are required for the simulation of non-visual effects of lighting. Sky data are generally not available; other types of data (e.g., spectral reflectance of surface materials, spectral power distribution of light sources) are also not easily available for most users of simulation tools. 
In addition to the validation of simulation tools mentioned above, other important research gaps include: developing tools for integrating photosensors into lighting/daylighting systems; determining the optimum wavelength resolution for the simulation of non-visual effects of lighting; and the implementation in simulation software of control algorithms, either for façade/daylighting or electric lighting systems.

\section{Conclusions}

Although integrated lighting systems may reduce lighting energy use in buildings, a broader web of non-energy impacts affecting occupant's overall health, comfort, and satisfaction may also guide technology investment goals when the entire lighting systems lifecycle is considered. Daylighting systems are separated from electric lighting systems, and both are characteristically detached from other systems such as safety, security, communications, and information systems. Being disconnected from the inputs and outputs of other building systems precludes the ability to acquire and utilize information about the occupation, status of systems, and interior and exterior environmental conditions. The outcome of this separation is that the standard building is not fulfilling the potential for creating dynamic and holistic lighting for building occupants.

This paper presents an effort to reveal the research, tools, and technical gaps preventing the full integration of electric lighting and daylighting with advanced façades through the coordination of lighting and window research activities. A fully integrated façade requires coordination between multiple research areas to ensure minimal duplication, prevent technology gaps, understand important system interactions, and prepare for market adoption. The results of the study and workshop captured current technology readiness levels (TRL), as well as research thrusts, implementation guidelines, and it identified research priorities, presenting an analysis of the current landscape of lighting metrics-and which metrics are in the critical path for developing integrated daylighting and electric lighting systems, and their design, installation, and technology guidelines. In addition, the study defined stakeholder coordination, pathways to interoperable technology, and the value of viewing the work of the individual research areas holistically rather than in isolation.

Author Contributions: Part 3, Section 3.1 Part 4, Section 4.1 were authored by G.D.T., while affiliated with the California Institute for Energy and Environment, University of California, Berkeley, prior to affiliation with PlanArchology LLC. Part 3, Sections 3.2 and 3.3 and Part 4, Sections 4.2 and 4.3 were primarily authored by R.G.D., Pacific Northwest National Laboratory. Part 3, Section 3.4 and Part 4, Section 4.4 were primarily authored by L.F., Lawrence Berkeley National Laboratory. Part 3, Section 3.5 and Part 4, Section 4.5 were authored by L.F. and T.W., Lawrence Berkeley National Laboratory. All authors have read and agreed to the published version of the manuscript.

Funding: This research was funded by the Assistant Secretary for Energy Efficiency and Renewable Energy, Building Technologies Office, of the U.S. Department of Energy under Contract No. DEAC02-05CH11231 (LBNL) and DE-AC05-76RL01830 (PNNL).

Institutional Review Board Statement: Not applicable.

Informed Consent Statement: Not applicable.

Acknowledgments: The authors would also like to thank the following organizations and people for their contributions. Tate Walker, OPN Architects; David Stade, FD Stonewater; Jason Wilkinson, McClennan Design; Clifton Lemon, Clifton Lemon Associates; HLB Lighting Design; Liam Buckley, Integrated Environmental Solutions, Ltd.; John Crowley, Attachment Energy Rating Council; Michael Martinez, and Emilie Hagen, Atelier 10; Belal Abboushi, Sarah Safranek, Andrea Wilkerson, PNNL; and, Christoph Gehbauer, Christian Kohler, Eleanor Lee, Bruce Nordman, Francis Rubinstein, Stephen Selkowitz, Jordan Shackelford, Anothai Thanachareonkit, LBNL. We would also like to acknowledge the contributions of the workshop attendees and their assistance in vetting the short- and mediumterm research priorities.

Conflicts of Interest: The authors declare no conflict of interest. 


\section{References}

1. Thomson, G.D.; Davis, R.G.; Fernandes, L.; Wang, T. Daylighting and Electric Lighting; California Institute for Energy and Environment, University of California: Berkeley, CA, USA; Pacific Northwest National Laboratory: Portland, OR, USA; Lawrence Berkeley National Laboratory: Berkeley, CA, USA; Portland, OR, USA, 2020; p. 135.

2. Indoor Air Division, Office of Atmospheric and Indoor Air Programs, Office of Air and Radiation, and Office of Research and Development prepared by U.S. Environmental Protection Agency. Report to Congress on Indoor Air Quality: Volume 2. Assessment and Control of Indoor Air Pollution. (Final Report); U.S. Environmental Protection Agency: Washington, DC, USA, 1989.

3. Alrubaih, M.; Zain, M.F.M.; Alghoul, M.; Ibrahim, N.L.N.; Shameri, M.A.; Elayeb, O. Research and Development on Aspects of Daylighting Fundamentals. Renew. Sustain. Energy Rev. 2013, 21, 494-505. [CrossRef]

4. Rubinstein, F.; Siminovitch, M.; Verderber, R. Fifty Percent Energy Savings with Automatic Lighting Controls. Ind. Appl. IEEE Trans. Ind. Appl. 1993, 29, 768-773. [CrossRef]

5. Bodart, M.; Herde, A. Global Energy Savings in Offices Buildings by the Use of Daylighting. Energy Build. 2002, 34, 421-429. [CrossRef]

6. Mardaljevic, J.; Heschong, L.; Lee, E. Daylight Metrics and Energy Savings. Light. Res. Technol. Light. Res. Technol. 2009, 41, 261-283. [CrossRef]

7. Ne'eman, E. A Comprehensive Approach to the Integration of Daylight and Electric Light in Buildings. Energy Build. 1984, 6, 97-108. [CrossRef]

8. Tsangrassoulis, A.; Synnefa, A. Integration of Electric Lighting-Daylighting. In SythLight Handbook; European Commission: Brussels, Belgium, 2004; p. 22.

9. Mustafa, H.; Faggal, A. Integration of Electric Lighting System in a Daylit-Building. In Proceedings of the PLEA2005-The 22nd Conference on Passive and Low Energy Architecture, Beirut, Lebanon, 13 November 2005; p. 6.

10. Guglielmetti, R.; Scheib, J. Challenges to Integrated Daylighting and Electric Lighting Simulation Methods in a Whole-Building Energy Simulation Context. In Proceedings of the SimBuild, Madison, WI, USA, 1 August 2012; p. 10.

11. Gentile, N.; Osterhaus, W.; Altomonte, S.; García Alvarez, M.; Garcia-Hansen, V.; Naves David Amorim, C.; Obradovic, B. Energy Saving Potential for Integrated Daylighting and Electric Lighting Design Via User-Driven Solutions: A Literature Review. In Proceedings of the 29th Quadrennial Session of the CIE, International Commission on Illumination, CIE, Washington DC, USA, 24 June 2019; pp. 205-215.

12. Campama Pizarro, R.; Gentile, N. A Case Study Addressing the Benefits of Integrated Solutions for Daylighting and Electric Lighting in the Retail Sector. In Proceedings of the ISES Solar World Congress 2019; International Solar Energy Society: Santiago, Chile, 2019; pp. 1-12.

13. Best Practices \& Case Studies-GSA Sustainable Facilites Tool. Available online: https://sftool.gov/learn/agency-practices/446/ iswg-case-studies (accessed on 19 December 2019).

14. Outcome-Based Pathways for Achieving Energy Performance Goals-National Institute of Building Sciences. Available online: https:/ / www.nibs.org/page/ outcomebasedpathways (accessed on 19 December 2019).

15. Case Studies IWBDG-Whole Building Design Guide. Available online: https://www.wbdg.org/additional-resources/casestudies (accessed on 19 December 2019).

16. Outcome-Based Energy Codes (Advanced Codes)—New Buildings Institute. Available online: https://newbuildings.org/code_ policy/outcome-based-energy-codes/ (accessed on 19 December 2019).

17. Energy-Performance-Based Acquisition for Commercial Buildings. Available online: https://buildingdata.energy.gov/cbrd/ energy_based_acquisition/ (accessed on 19 December 2019).

18. LEED Green Building Certification I USGBC. Available online: https:/ / new.usgbc.org/leed (accessed on 19 December 2019).

19. USGBC Announces Extension of LEED 2009/U.S. Green Building Council. Available online: https://www.usgbc.org/articles/ usgbc-announces-extension-leed-2009 (accessed on 20 February 2020).

20. USGBC: LEED Version 3. Available online: https:/ /web.archive.org/web/20100225022230/http://www.usgbc.org/DisplayPage. aspx?CMSPageID=1970 (accessed on 20 February 2020).

21. U.S. Green Building Council. LEED 2009 for New Construction and Major Renovations. Available online: https:/ /www.usgbc. org/ShowFile.aspx?DocumentID=5546 (accessed on 20 February 2020).

22. IEQc6.1. Available online: https:/ / leeduser.buildinggreen.com/credit/NC-2009/IEQc6.1 (accessed on 20 February 2020).

23. IEQc6.2. Available online: https://leeduser.buildinggreen.com/credit/NC-2009/IEQc6.2 (accessed on 20 February 2020).

24. NC-2009 IEQc7.1: Thermal Comfort-Design / LEEDuser. Available online: https:/ /leeduser.buildinggreen.com/credit/NC-2009 /IEQc7.1\#tab-credit-language (accessed on 20 December 2019).

25. NC-2009 IEQc7.2: Thermal Comfort-Verification I LEEDuser. Available online: https://leeduser.buildinggreen.com/credit/NC2009/IEQc7.2\#tab-credit-language (accessed on 20 December 2019).

26. NC-2009 IEQc8.1: Daylight and Views-Daylight I LEEDuser. Available online: https:/ /leeduser.buildinggreen.com/credit/NC2009/IEQc8.1\#tab-credit-language (accessed on 19 December 2019).

27. NC-2009 IEQc8.2: Daylight and Views-Views I LEEDuser. Available online: https://leeduser.buildinggreen.com/credit/NC-2009 /IEQc8.2\#tab-credit-language (accessed on 19 December 2019).

28. International Lighting Vocabulary; CIE Publication S 017:2020; Commission Internationale de L'Eclairage (CIE): Vienna, Austria, 2020. 
29. Eble-Hankins, M. VCP and UGR Glare Evaluation Systems: A Look Back and a Way Forward. Leukos 2004, 1, 7-38. [CrossRef]

30. Ashdown, I. Sensitivity Analysis of Glare Rating Metrics. LEUKOS J. Illum. Eng. Soc. N. Am. 2005, 2, 115-122. [CrossRef]

31. Van den Wymelenberg, K.; Inanici, M. A Critical Investigation of Common Lighting Design Metrics for Predicting Human Visual Comfort in Offices with Daylight. LEUKOS 2014, 10, 145-164. [CrossRef]

32. Wienold, J.; Iwata, T.; Sarey Khanie, M.; Erell, E.; Kaftan, E.; Rodriguez, R.; Yamin Garreton, J.; Tzempelikos, T.; Konstantzos, I.; Christoffersen, J.; et al. Cross-Validation and Robustness of Daylight Glare Metrics. Light. Res. Technol. 2019, 51, $983-1013$. [CrossRef]

33. Kent, M.; Fotios, S. The Effect of a Pre-Trial Range Demonstration on Subjective Evaluations Using Category Rating of Discomfort Due to Glare. LEUKOS 2019, 1-16. [CrossRef]

34. Fotios, S.; Kent, M. Measuring Discomfort from Glare: Recommendations for Good Practice. LEUKOS 2020, 1-21. [CrossRef]

35. Wienold, J.; Christoffersen, J. Evaluation Methods and Development of a New Glare Prediction Model for Daylight Environments with the Use of CCD Cameras. Energy Build. 2006, 38, 743-757. [CrossRef]

36. Cai, H. High Dynamic Range Photogrammetry for Synchronous Luminance and Geometry Measurement. Light. Res. Technol. 2013, 45, 230-257. [CrossRef]

37. Cai, H.; Chung, T.M. Improving the Quality of High Dynamic Range Images. Light. Res. Technol. 2011, 43, 87-102. [CrossRef]

38. Suk, J.Y.; Schiler, M.; Kensek, K. Development of New Daylight Glare Analysis Methodology Using Absolute Glare Factor and Relative Glare Factor. Energy Build. 2013, 64. [CrossRef]

39. Van Den Wymelenberg, K.; Inanici, M. Evaluating a New Suite of Luminance-Based Design Metrics for Predicting Human Visual Comfort in Offices with Daylight. LEUKOS 2016, 12, 113-138. [CrossRef]

40. Van den Wymelenberg, K.; Inanici, M.; Johnson, P. The Effect of Luminance Distribution Patterns on Occupant Preference in a Daylit Office Environment. LEUKOS 2010, 7, 103-122. [CrossRef]

41. Safranek, S.; Davis, R.G. Sources of Error in HDRI for Luminance Measurement: A Review of the Literature. LEUKOS 2021, 17, 187-208. [CrossRef]

42. International WELL Building Institute. WELL v2. 2018. Available online: https://v2.wellcertified.com/v/en/overview (accessed on 5 September 2019).

43. Lucas, R.; Peirson, S.; Berson, D.; Brown, T.; Cooper, H.; Czeisler, C.; Figueiro, M.; Gamlin, P.; Lockley, S.; O’Hagan, J.; et al. Measuring and Using Light in the Melanopsin Age. Trends Neurosci. 2013, 37. [CrossRef]

44. CIE S 026/E:2018 CIE System for Metrology of Optical Radiation for IpRGC-Influenced Responses to Light; International Commission on Illumination (CIE): Vienna, Austria, 2018.

45. CIE Position Statement on Non-Visual Effects of Light: Recommending Proper Light at the Proper Time 2019, 2nd ed.; Commission Internationale de L'Eclairage (CIE): Vienna, Austria, 2019.

46. Rea, M.; Figueiro, M. Light as a Circadian Stimulus for Architectural Lighting. Light. Res. Technol. 2016, 50. [CrossRef]

47. Rea, M.; Figueiro, M.; Bierman, A.; Bullough, J. Circadian Light. J. Circadian Rhythm. 2010, 8. [CrossRef]

48. Rea, M. Toward a Definition of Circadian Light. J. Light Vis. Environ. 2011, 35, 250-254. [CrossRef]

49. Lewy, A.; Wehr, T.; Goodwin, F.; Newsome, D.; Markey, S. Light Suppresses Melatonin Secretion in Humans. Science 1981, 210, 1267-1269. [CrossRef]

50. Glickman, G.; Hanifin, J.; Rollag, M.; Wang, J.; Cooper, H.; Brainard, G. Inferior Retinal Light Exposure Is More Effective than Superior Retinal Exposure in Suppressing Melatonin in Humans. J. Biol. Rhythms 2003, 18, 71-79. [CrossRef]

51. Brown, T.; Brainard, G.; Cajochen, C.; Czeisler, C.; Hanifin, J.; Lockley, S.; Lucas, R.; Munch, M.; O’Hagan, J.; Peirson, S.; et al. Recommendations for Healthy Daytime, Evening, and Night-Time Indoor Light Exposure. Preprints 2020. [CrossRef]

52. Wilkerson, A.; Davis, R.G.; Clark, E. Tuning Hospital Lighting: Evaluating Tunable LED Lighting at the Swedish Hospital Behavioral Health Unit in Seattle; Pacific Northwest National Laboratory: Richland, WA, USA, 2017; p. 25.

53. Davis, R.G.; Wilkerson, A. Tuning the Light in Classrooms: Evaluating Trial LED Lighting Systems in Three Classrooms at the CarrolltonFarmers Branch Independent School District in Carrollton, TX; Pacific Northwest National Laboratory: Richland, WA, USA, 2017; p. 30.

54. Safranek, S.F.; Davis, R.G. Evaluating Tunable Lighting in Classrooms: Trial LED Lighting Systems in Three Classrooms in the Folsom Cordova Unified School District; Pacific Northwest National Laboratory: Richland, WA, USA, 2018; PNNL-27806.

55. Safranek, S.; Collier, J.M.; Wilkerson, A.; Davis, R.G. Energy Impact of Human Health and Wellness Lighting Recommendations for Office and Classroom Applications. Energy Build. 2020, 226, 110365. [CrossRef]

56. Fernandes, L.L.; Lee, E.S.; DiBartolomeo, D.L.; McNeil, A. Monitored Lighting Energy Savings from Dimmable Lighting Controls in The New York Times Headquarters Building. Energy Build. 2014, 68, 498-514. [CrossRef]

57. Lee, E.S.; Fernandes, L.L.; Wang, T.; Selkowitz, S.E. Demonstration of Energy Efficient Retrofits for Lighting and Daylighting in New York City Office Buildings; Lawrence Berkeley National Laboratory: Berkeley, CA, USA, 2017; p. 208.

58. Koyle, B.; Papamichael, K. Dual-Loop Photosensor Control Systems: Reliable, Cost-Effective Lighting Control for Skylight Applications; American Council for an Energy-Efficient Economy (ACEEE): Asilomar, CA, USA, 2010; p. 10.

59. Blue Iris Labs Blue Iris Labs. Available online: https://blueirislabs.com/ (accessed on 28 April 2021).

60. Selkowitz, S.; Hitchcock, R.; Mitchell, R.; McClintock, M.; Settlemyer, K. COMFEN-Early Design Tool for Commercial Facades and Fenestration Systems; Lawrence Berkeley National Laboratory: Berkeley, CA, USA, 2014; p. 120. 
61. Lighting Analysts AGI32. Available online: https://lightinganalysts.com/software-products/agi32/overview/ (accessed on 28 April 2021).

62. Ward, L.G.; Shakespeare, R. Rendering with Radiance: The Art and Science of Lighting Visualization; Morgan Kaufman: San Francisco, CA, USA, 1998.

63. Jakubiec, J.A.; Reinhart, C.F. DIVA 2.0: Integrating Daylight and Thermal Simulations Using Rhinoceros 3D, Daysim and Energyplus. In Proceedings of the Building Simulation 2011: 12th Conference of International Building Performance Simulation Association, Sydney, Australia, 14-16 November 2011; p. 8.

64. Daylighting Innovations SPOT. Available online: https://www.daylightinginnovations.com/spot-home (accessed on 28 April 2021).

65. Fernandes, L.L.; Lee, E.S.; Ward, G. Lighting Energy Savings Potential of Split-Pane Electrochromic Windows Controlled for Daylighting with Visual Comfort. Energy Build. 2013, 61, 8-20. [CrossRef]

66. University of Washington LARK. Available online: https://faculty.washington.edu/inanici/Lark/Lark_home_page.html (accessed on 28 April 2021).

67. Solemma ALFA. Available online: https://www.solemma.com/alfa (accessed on 28 April 2021).

68. Veitch, J.A.; Davis, R.G. Lighting Research Today: The More Things Change, the More They Stay the Same. LEUKOS 2019, 15, 77-83. [CrossRef]

69. Uttley, J. Power Analysis, Sample Size, and Assessment of Statistical Assumptions-Improving the Evidential Value of Lighting Research. LEUKOS 2019, 15, 143-162. [CrossRef]

70. Lawrence Berkeley National Laboratory International Glazing Database. Available online: https://windows.lbl.gov/software/ igdb (accessed on 28 April 2021).

71. Jakubiec, J.A. Building a Database of Opaque Materials for Lighting Simulation. In Proceedings of the 36th International Conference on Passive and Low Energy Architecture; Passive and Low Energy Architecture: Los Angeles, CA, USA, 2016 ; p. 6.

72. Lawrence Berkeley National Laboratory Complex Glazing Database. Available online: https://windows.lbl.gov/software/cgdb (accessed on 28 April 2021). 